\title{
Memory and Utterance Temporality
}

\section{Память и темпоральность высказывания}

Viktoriya Oschepkova ${ }^{1}$

Dr. in Philology, Professor, Head of Department of English Philology

\section{Виктория Ощепкова ${ }^{\mathbf{1}}$}

доктор филологических наук, профессор, заведующий кафедрой английской филологии

E-mail: oschep2014@yandex.ru

orcid.org/0000-0003-0266-7039

Irina Tivyaeva ${ }^{2}$

Dr. in Philology,

Assistant Professor
Ирина Тивьяева ${ }^{2}$

доктор филологических наук, доцент

E-mail: tivyaeva@yandex.ru orcid.org/0000-0002-6316-784X

Researcher ID H-9075-2017

Scopus Author ID 57103732800

${ }^{1}$ Moscow Region State University

10A, Radio Str., Moscow, Russian, 105005

${ }^{2}$ Moscow City University, Department of Linguistics and

Translation Studies

4-1, $2^{\text {nd }}$ Sel'skokhozyajstvennyj proezd, Moscow, Russian, 129226
${ }^{1}$ ГОУ ВО Московской области «Московский государственный областной университет» ул. Радио, 10А, Москва, Россия, 105005

\author{
${ }^{2}$ ГАОУ ВО г. Москвы «Московский \\ городской педагогический \\ университет» \\ 2-ой Сельскохозяйственный \\ проезд, 4/1, Москва, Россия, 129226
}

Original manuscript received September 10, 2018

Revised manuscript accepted August 09, 2019 


\section{ABSTRACT}

Objective. The paper presents a psycholinguistic perspective of the memory-time linkage problem extensively discussed by cognitive psychologists. Accepting the concept of personal memory as a linguocognitive system including the processes of encoding, storing, retrieval, and forgetting, the authors aim to examine how these processes are verbalized in regard to their temporal orientation. The present study is specifically focused on analyzing the morphological component of the verbal code (namely, tense forms) used by English speakers to represent their mnemonic experiences at each stage of cognitive processing.

Methods. Research procedures consisted in content analysis of each empirical item, distribution of sample fragments in accordance with the mnemonic situation type, structural and morphological analysis of mnemonic utterances and finding correlation between the type of a mnemonic utterance and the organization of its temporal structure.

Materials. The empirical database used in the research counts 7.500 communicative contexts selected from publicly available English sources and contains fragments of fiction, mass media and computer-mediated communication. The primary selection principle required that each research item should meet the criteria of the mnemonic situation, that is, include 1) the subject of the mnemonic experience, 2) the memory process being verbalized, 3) the mnemonic utterance as a verbal representation of the mnemonic content.

Results. The yielded results demonstrate the role of present, past and future tense forms in shaping the temporal structure of mnemonic utterances in English, suggest correlations between the temporal type of a mnemonic utterance and the cognitivecommunicative conditions under which it was produced, which allows concluding that memory association with the past is an empirically ungrounded stereotype while the temporal structure of a mnemonic utterance is a heterogeneous one.

Key words: memory, mnemonic processes, mnemonic utterance, time, temporality, tense forms.

\section{Введение}

Со времен античности память не мыслится без времени и вне времени. Темпоральность памяти по-прежнему остается одним из актуальных вопросов современного гуманитарного знания, привлекая внимание лингвистов, психологов, философов и литературоведов. Указывая на тесную связь памяти и времени, исследователи часто по умолчанию рассматривают прошлое как сферу реализации мнемических процессов, фактически отождествляя память и воспоминание. Так, например, У. Кинш пишет: «Мапу 
texts in memory are specified as past. These include historical knowledge (Caesar invaded Gaul) and personally experienced episodes (I heard the Grieg piano concerto yesterday)» (Kintsch, 2014: 64). Однако в соответствии с представлениями современной психологии память не ограничивается ретроспективной направленностью и не сводится к воспоминаниям, но являет собой комплексное психокогнитивное образование - систему организации и хранения личного опыта, базирующуюся на процессах запоминания, хранения, воспроизведения и утраты информации (Середа, 1985; Огородникова, 2012).

Специфика вербальной манифестации мнемической деятельности в ее связи с темпоральной ориентацией в последнее время активно изучается когнитивными психологами. В частности, были установлены связи между характеристиками удерживаемого в памяти события и особенностями вербального представления его длительности во времени (Block \& Gruber, 2014; Faber \& Gennari, 2015), выявлены зависимости операций памяти от темпоральной организации мнемического содержания (Clewett \& Davachi, 2017; Gershman, 2017; Howard, 2018; Wang \& Gennari, 2019). При этом в психологических исследованиях темпорального аспекта памяти основное внимание уделяется, в первую очередь, объективируемым посредством языка характеристикам мнемической деятельности и свойствам информационных актантов мнемических процессов, тогда как для психолингвистики и лингвистики в целом важно изучить механизм экспликации мнемического содержания в языковых знаках различных уровней.

Такие попытки предпринимаются зарубежными психолингвистами, в работах которых проблематика темпоральности мнемической деятельности и ее отражения в языке рассматривалась в первую очередь в аспекте структурной организации текстов воспоминаний и процесса речепонимания (Fuhrman \& Wyer, 1988; Xu \& Kwok, 2019), а также в контексте изучения процессов речепорождения и речевого развития у детей (Harner, 1976; Graybeal, 1981; Moore \& Johnston, 1993; Copmann \& Griffith, 1994).

В целом, анализ эмпирических данных и экспериментально полученные результаты позволяют заключить, что темпоральность удерживаемых в памяти событий воспринимается носителем мнемического опыта субъективно, a eе интерпретация и 
хронологическое упорядочивание мнемического содержимого определяются комплексом лингвистических и психолингвистических факторов, в том числе воздействием когнитивно-коммуникативного контекста вербализации мнемических переживаний (Тивьяева, 2017).

До настоящего времени внимание специалистов было приковано преимущественно к структурно-организационному и лексико-семантическому компонентам вербального кода, используемого для манифестации мнемической деятельности в процессе речевого общения. Интерес к морфологическому компоненту вербального кода памяти появился относительно недавно. Основой для исследования морфологических маркеров памяти послужили идеи У. Чейфа (Chafe, 1973) о возможности репрезентации памяти языковыми категориями, которые находят воплощение в грамматических формах. Так, например, работы Ф. Кроуна (Crone, 2015, 2017) посвящены изучению особенностей функционирования мнемических императивов («mnemonic imperatives»), то есть императивных высказываний с мнемическими глаголами, значение которых не может быть описано в терминах стандартных теорий значения императивов. А. Сморти и его соавторы выявили ряд закономерностей, регулирующих употребление личных местоимений первого лица в мнемических нарративах (Smorti et al., 2016). На участие местоимений в передаче ментальных процессов и состояний, в том числе процессов памяти, указывают также Дж.У. Пеннбейкер (Pennebaker, 2013) и А.А. Артюнина (2013).

Тем не менее, несмотря на появление новых перспективных исследований, проблема репрезентации мнемических процессов на морфологическом уровне не получила исчерпывающего решения, поскольку вопросы грамматического оформления темпоральности памяти на настоящий момент образуют зону лакунарности, тогда как время всегда было ключевым элементом концептуализации памяти в языке. Во всех научных концепциях категория времени неизменный спутник памяти и личного опыта. Г.Е. Крейдлин отмечает, что «жизненный опыт, психическая деятельность, все наиболее сильные впечатления и эмоциональные переживания человека связаны с переживаниями времени» (Крейдлин, 1997: 139).

С учетом вышесказанного представляется целесообразным рассмотреть, каким образом темпоральная ориентация 
мнемических процессов манифестируется на морфологическом уровне в процессе речевого взаимодействия на английском языке. Поскольку доминирующим средством выражения темпоральности признаются видовременные формы глагола, в настоящей работе предпринимается попытка определить роль глагольных форм в маркировании временно́й ориентации процессов памяти при трансляции мнемического содержания в условиях естественной коммуникации на английском языке.

Достижение указанной цели потребовало решения ряда теоретико-методологических и эмпирических задач, а именно: 1) определения формата вербального отражения мнемической деятельности субъекта; 2) выбора материала исследования и сбора фактических языковых данных, адекватных поставленной цели; 3) анализа морфологической структуры фрагментов, вошедших в авторскую картотеку, инвентаризации глагольных форм в пределах каждого фрагмента, определения их значимости и потенциала при маркировании мнемической деятельности; 4) обработки полученных результатов и формулирования выводов о функционировании глагольных форм в качестве морфологических маркеров индивидуальной памяти.

\section{Материал и методика исследования}

Сбор фактических языковых данных, составивших эмпирическую базу исследования, осуществлялся с опорой на теоретические положения современной лингвистики о способах и формах языкового отображения процессов памяти. В качестве инструмента анализа была избрана «мнемическая ситуация» (Исхакова \& Хомякова, 2009; Рогачёва, 2003) как когнитивнокоммуникативное пространство вербализации индивидуальной памяти. К числу облигаторных компонентов мнемической ситуации (далее МС) мы относим следующие: 1) субъекта МС - лицо, осуществляющее мнемическую деятельность, 2) мнемическое высказывание - высказывание, порожденное в рамках МС и выступающее средством трансляции мнемического содержания в естественной коммуникации, 3) собственно вербализуемый мнемический процесс. Таким образом, коммуникативный контекст 
регистрировался в картотеке, если он иллюстрировал вербальное взаимодействие участников MC и содержал мнемическое высказывание любого типа - мнемическое диалогическое единство, мнемический монолог или мнемический нарратив (подробнее о типах мнемического высказывания см. (Тивьяева, 2013)).

В основу авторской картотеки, составившей эмпирическую базу исследования, вошли 7500 коммуникативных контекстов, отобранных из разнотипных англоязычных источников, в том числе отрывки из художественной и документальной прозы, a также фрагменты публичной, массовой и компьютерноопосредованной коммуникации. Выбор в пользу англоязычного фактического материала продиктован, в первую очередь, широкой распространенностью английского языка в современном мире, a, следовательно, доступностью и многообразием источников языковых данных, а также следованием междисциплинарной тенденции исследования вербализации мнемической деятельности средствами английского языка. В картотеку включались текстовые фрагменты, принадлежащие исключительно англоязычным авторам. В целях предотвращения попадания в выборку высказываний, для продуцентов которых английский язык не является родным, выбор источников определялся также в соответствии с географическим принципом.

Первый этап обработки эмпирических данных предполагал распределение отобранных коммуникативных контекстов в соответствии с типом процесса памяти, вербализуемого в рамках данной МC (запоминание, хранение, воспоминание и забывание), что позволило оценить потенциал употребления глагольных форм для маркирования конкретных мнемических процессов.

На следующем этапе решения исследовательских задач был осуществлен контент-анализ и морфологический анализ темпоральной структуры каждого мнемического высказывания в рамках зарегистрированных коммуникативных контекстов с целью инвентаризации глагольных форм, выявления принципов их употребления и определения потенциала при маркировании мнемической деятельности.

Дальнейшие этапы исследования включали поиск и установление соответствий между типом мнемического высказывания и организацией его темпоральной структуры. 


\section{Результаты и обсуждение}

На первом этапе исследования зарегистрированные в картотеке коммуникативные контексты были распределены на четыре группы в соответствии с маркируемым процессом памяти, после чего был осуществлен анализ функционирования глагольных форм в мнемических высказываниях в каждой группе. Вопреки стереотипным, но не обоснованным с точки зрения современных концепций памяти, представлениям об объективации мнемических процессов исключительно посредством форм прошедшего времени, результаты аналитической обработки фактического языкового материала показали, что на морфологическом уровне вербализаторами процессов памяти в англоязычной коммуникации могут выступать глагольные формы, принадлежащие сфере как прошлого, так и настоящего и будущего. Полученные данные об участии видо-временных форм английского глагола в репрезентации мнемических процессов отражены в таблице 1.

Таблица 1. Потенциал видо-временных форм английского глагола при маркировании процессов памяти в рамках мнемического высказывания

\begin{tabular}{|c|c|c|c|c|}
\hline Маркируемый мнемический процесс & 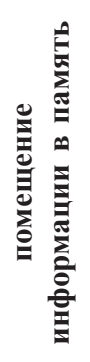 & 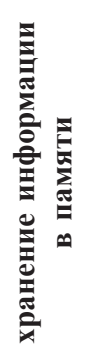 & 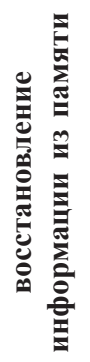 & 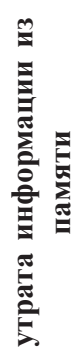 \\
\hline \multicolumn{5}{|l|}{ Времена группы Present } \\
\hline Present Indefinite & + & + & + & + \\
\hline Present Continuous & + & + & + & + \\
\hline Present Perfect & & & + & \\
\hline Present Perfect Continuous & & & + & \\
\hline \multicolumn{5}{|l|}{ Времена группы Past } \\
\hline Past Indefinite & & + & + & + \\
\hline Past Continuous & & + & + & + \\
\hline Past Perfect & & & + & + \\
\hline Past Perfect Continuous & & & + & \\
\hline
\end{tabular}


Времена группы Future

Future Indefinite

Future Continuous

В соответствии с полученными результатами, в маркировании мнемических процессов на морфологическом уровне задействовано десять видо-временных форм английского глагола, из которых только четыре формы принадлежат сфере прошедшего, таким образом, говорить об их абсолютном доминировании над другими глагольными формами не приходится. При этом наибольшим потенциалом относительно манифестирования процессов памяти в англоязычной коммуникации обладают формы Present Indefinite, Present Continuous и Future Indefinite, зарегистрированные нами в качестве морфологических маркеров каждого из этапов мнемической обработки информации. Формы Past Indefinite, Past Continuous и Future Continuous также принимают активное участие в вербализации мнемического опыта, выступая маркерами всех процессов памяти, за исключением запоминания.

Формы будущего времени, являясь, вероятно, наименее ожидаемыми в ситуациях, связанных с вербализацией мнемического содержимого, несмотря на относительно невысокую встречаемость в высказываниях участников мнемической ситуации, органично вписываются в подобные контексты, так как они не только номинируют соответствующий процесс памяти, но и нередко дополнительно характеризуют его как желаемый, ожидаемый, планируемый и т.д. в силу своей ирреальной природы. Комментируя употребление форм будущего времени в автобиографических нарративах, воспроизводящих личных опыт нарратора, Э. Окс (Ochs, 1994) отмечает, что появление форм со значением будущего в подобных контекстах указывает на то, что такие высказывания видятся субъектом не как реконструкция прошлого опыта, но также как преконструкция опыта будущего.

Например, в следующем фрагменте формы будущего времени глагола to remember указывают на намерение нарратора сохранить в памяти информацию об увиденном. Процесс хранения информации в данном случае видится не как реальный, а как планируемый субъектом на долгосрочную перспективу и воспринимаемый им в позитивном ключе. 
Still, with all the fascination we were experiencing with the temples and tombs of Luxor and Aswan, it is the Pyramids of Giza, and my first view of the caped top of the Great Pyramid of Lhufu outside of Cairo (the largest pyramid in Egypt) that I will most remember. I will remember it for its sheer grandeur (2.3 million limestone blocks, each weighing roughly 2.5 tons). I will remember it for the feeling I had while walking around it trying to fathom its construction. I will remember how it rose from the Giza Plateau, from the congested streets and their mass of traffic, with the great decomposing Sphinx acting as its watchdog. I will remember how Egypt has grown around this ancient piece of its history, living beside it, on top of it, constructing parking lots to hold the tour buses that descend upon it in waves. (Andersen J. The Tomb of Ahmed Saeed)

Наименьшие возможности в отношении объективации мнемической деятельности на морфологическом уровне наблюдаются у перфектных и перфектно-длительных форм. Так, в частности, формы Future Perfect и Future Perfect Continuous не были зафиксированы ни в одном из коммуникативных фрагментов, включенных в нашу выборку. Формы Present Perfect, Present Perfect Continuous и Past Perfect Continuous способны выступать сигналами процесса восстановления информации из памяти, однако количество зарегистрированных фрагментов с их участием незначительно. Из перфектных форм высокой встречаемостью отличается форма Past Perfect, стабильно репрезентирующая процессы восстановления и утраты информации из памяти.

Важно отметить, что причисляя ту или иную глагольную форму к морфологическим маркерам мнемических процессов, мы не подразумеваем ее абсолютного доминирования над другими формами в рамках отдельно взятого мнемического высказывания, но признаем ее участие в формировании темпорального плана высказывания. При этом ряд форм можно охарактеризовать как стержневые, так как именно они задают основу темпоральной локализации высказывания, тогда как другие формы, принадлежащие той же временной сфере, выполняют второстепенные функции, не являясь ведущими. Например, среди времен группы прошедшего стержневым в мнемических высказываниях различных типов является Past Indefinite, тогда как формам Past Perfect, Past Continuous и Past Perfect Continuous отводятся роли второго плана. 
Следующий фрагмент иллюстрирует функционирование видовременных форм глагола в мнемическом нарративе.

I sat on the swing and pushed off and tried to remember what I could. The school was familiar. I had a flash of walking down the hall to the cafeteria, jumping between the black and white checked tiles. My second-grade teacher was Ms. Klee. Someone in my class had spilled water on my art project, and when I cried, Ms. Klee let me be the leader of the line for the whole week. I'd broken my arm in this playground. I'd been standing on the swing, and when I jumped off, my pants got snagged in the chain, and I fell face-first and broke the fall by sticking my arm out. My memories felt almost like photographs, short images, some bright and clear, others distant and fuzzy. Some disappeared entirely the moment I tried to focus on them. There were also big black holes. I could remember breaking my arm, but when I tried to remember Mom taking me to the hospital, there was nothing. I remembered Ms. Klee being nice to me, but I couldn't even remember who my teacher was in fourth grade. (Cook E. Remember)

В рассматриваемом примере события, излагаемые нарратором, лежат в поле прошлого. Соответствующий темпоральный план формируется, в первую очередь, формой Past Indefinite, число употреблений которой во фрагменте равно 20 , или $77,0 \%$ от общего количества глагольных форм в отрывке. Однако, помимо Past Indefinite, темпоральный план мнемического нарратива формируется также другими глагольными формами, относящимися к сфере прошедшего, а именно: Past Perfect (2 формоупотребления, или 7,7\% от общего количества), Past Perfect Continuous (1 формоупотребление, или 3,8\% от общего количества) и модальным глаголом could co значением действия в прошлом (3 формоупотребления, или 11,5\% от общего количества). Таким образом, не являясь стержневыми для данного мнемического высказывания, формы Past Perfect, Past Perfect Continuous и модальный глагол could, тем не менее, принимают участие в маркировании мнемической деятельности на морфологическом уровне. На их совокупную долю приходится 6 формоупотреблений из 26 , что составляет около $23,0 \%$ от общего количества глагольных форм в рассматриваемом фрагменте.

Представленный выше пример имеет однородную темпоральную структуру, то есть все глагольные формы, локализующие описываемые события во времени, создают единый 
темпоральный план - план прошлого. Однако, как показывают результаты анализа эмпирических данных, монотемпоральность не единственный способ организации темпоральной структуры мнемического высказывания. Среди коммуникативных контекстов, входящих в авторскую картотеку, нами были зарегистрированы фрагменты с неоднородной темпоральной структурой, характеризующейся наличием двух или трех темпоральных планов, что позволило нам выделить три типа темпоральной структуры мнемического высказывания: монотемпоральный, битемпоральный и политемпоральный.

На последующих этапах аналитической обработки языкового материала были выявлены корреляционные связи между типом мнемического высказывания и особенностями его темпоральной организации. Так, например, среди мнемических диалогических единств (далее МДЕ) нами не было зафиксировано ни одного высказывания, темпоральная структура которого включала бы сразу три временных плана. Также было установлено, что отдельным типам мнемических высказываний, характеризующихся битемпоральной или политемпоральной структурой, соответствуют рекуррентные комбинации временных планов. Например, для мнемического нарратива с битемпоральной структурой единственно возможной является комбинация «настоящее + прошлое». Комбинация «настоящее + будущее» для данного типа мнемического высказывания не была зарегистрирована ни разу, при том, что она лежит в основе одного из стабильно воспроизводимых типов темпоральной структуры мнемического монолога.

Особенности темпоральной структуры мнемических высказываний различных типов отражены в таблице 2.

Таблица 2. Темпоральная структура мнемического высказывания

\begin{tabular}{|c|c|c|c|}
\hline \multirow{2}{*}{$\begin{array}{c}\text { Тип мнемического } \\
\text { высказывания }\end{array}$} & \multicolumn{3}{|c|}{ Тип темпоральной структуры } \\
\hline & монотемпоральный & битемпоральный & политемпоральный \\
\hline $\begin{array}{l}\text { Мнемическое } \\
\text { диалогическое } \\
\text { высказывание }\end{array}$ & & & \\
\hline $\begin{array}{l}\text { МДЕ «побуждение } \\
\text { к запоминанию - } \\
\text { реакция» }\end{array}$ & - & $\begin{array}{l}\text { 1) ирреальное + } \\
\text { настоящее } \\
\text { 2) ирреальное + } \\
\text { будущее }\end{array}$ & - \\
\hline
\end{tabular}




\begin{tabular}{|c|c|c|c|}
\hline $\begin{array}{l}\text { МДЕ «напоминание - } \\
\text { реакичия» }\end{array}$ & $\begin{array}{l}\text { 1) настоящее } \\
\text { 2) будущее }\end{array}$ & $\begin{array}{l}\text { 1) настоящее + } \\
\text { будущее } \\
\text { 2) ирреальное + } \\
\text { будущее } \\
\text { 3) ирреальное + } \\
\text { настоящее }\end{array}$ & - \\
\hline $\begin{array}{l}\text { МДЕ «запрос } \\
\text { информачии из } \\
\text { памяти - реакцияя }\end{array}$ & $\begin{array}{l}\text { 1) настоящее } \\
\text { 2) прошлое }\end{array}$ & $\begin{array}{l}\text { настоящее + } \\
\text { прошлое }\end{array}$ & - \\
\hline $\begin{array}{l}\text { МДЕ «побуждение к } \\
\text { забыванию - реакичия» }\end{array}$ & - & $\begin{array}{l}\text { 1) ирреальное + } \\
\text { настоящее } \\
\text { 2) ирреальное + } \\
\text { будущее }\end{array}$ & - \\
\hline Мнемический монолог & $\begin{array}{l}\text { 1) настоящее } \\
\text { 2) прошлое } \\
\text { 3) будущее }\end{array}$ & $\begin{array}{l}\text { 1) настоящее+ } \\
\text { прошлое } \\
\text { 2) настоящее + } \\
\text { будущее }\end{array}$ & $\begin{array}{l}\text { настоящее + } \\
\text { прошлое + } \\
\text { будущее }\end{array}$ \\
\hline $\begin{array}{l}\text { Мнемический } \\
\text { нарратив }\end{array}$ & прошлое & $\begin{array}{l}\text { настоящее + } \\
\text { прошлое }\end{array}$ & $\begin{array}{l}\text { настоящее + } \\
\text { прошлое + } \\
\text { будущее }\end{array}$ \\
\hline
\end{tabular}

На основании полученных результатов можно сделать вывод о том, что самым распространенным типом темпоральной структуры мнемического высказывания является битемпоральный, сочетающий в себе два временных плана. Данный тип был зарегистрирован нами для всех видов высказываний в мнемической ситуации. Битемпоральная структура представлена следующими комбинациями:

1) ирреальное + настоящее,

2) ирреальное + будущее,

3) настоящее + будущее,

4) настоящее + прошлое.

Специфической особенностью данного типа темпоральной организации высказывания является наличие плана ирреальности, или временно́й неопределенности, противопоставленного плану временно́й определенности, отражающему локализацию действия в прошлом, настоящем или будущем. План временно́й неопределенности формируется глагольными формами с модальным значением, соответственно, мнемический процесс, объективированный в мнемическом высказывании с подобной морфологической структурой, мыслится говорящим как требуемый или желаемый. Рассмотрим следующие примеры: 
"Just remember that she might still be a little doped up, though, since I had to administer some sedatives so she'd be calm for the X-ray and to help with the pain.» (Sparks N. The Choice)

"And you might all remember that you're relying on me for references.» (Kinsella S. Remember Me?)

"I will agree to this on one condition, you must forget me.» (Andrews N. Diviner's Prophecy: A Historical Romance Fantasy Series)

Данные фрагменты являются инициирующими репликами МДЕ «побуждение к запоминанию - реакция», «напоминание реакция» и «побуждение к забыванию - реакция» соответственно, стимулирующими запуск мнемических процессов помещения информации в память, хранения и утраты информации. В приведенных примерах значение временно́й неопределенности выражается посредством императива и модальных глаголов «might» и «must» и относится к ирреальному плану возможности и побудительности. Таким образом, выбор глагольных форм, принадлежащих к неопределенному временно́му плану, определяется исходной интенцией инициатора коммуникативного обмена в мнемической ситуации, рассматривающего обращение к памяти партнера по коммуникации как действие желательное или необходимое.

Сочетание планов временно́й определенности и временно́й неопределенности в темпоральной структуре мнемического высказывания было зафиксировано нами только у МДЕ, диалогическая форма которого предоставляет коммуникантам больше возможностей для передачи информации о событиях, не локализованных во времени.

Битемпоральную структуру можно считать универсальным типом грамматической организации мнемического высказывания, так как различные ее комбинации из числа указанных выше были зарегистрированы нами как для МДЕ, так и для мнемического монолога и мнемического нарратива (см. примеры ниже).

Следующий пример представляет собой МДЕ «запрос информации из памяти - реакция», темпоральная структура которого организована в соответствии с принципом битемпоральности и подчиняется схеме «настоящее + будущее». Инициирующая реплика содержит обращение к памяти субъекта мнемической ситуации, относящееся к плану настоящего. Инициатор диалогического 
обмена интересуется наличием в памяти собеседника определенных данных. Битемпоральность МДЕ проявляется в ответной реплике, где носитель мнемического опыта подтверждает факт хранения запрашиваемых сведений в настоящий момент и декларирует намерение поддерживать их в актуальном состоянии в будущем.

"Do you remember what he did look like?»

"Anastasia, this isn't a part of my life I revisit very often. Yes, I remember what he looked like. I'll never forget him.» (James E.L. Fifty Shades Darker)

Следующий пример - фрагмент мнемического монолога, автор которого делится воспоминаниями о последних годах жизни своей жены, проведенных в борьбе с онкологическим заболеванием. В основе структуры рассматриваемого монолога лежит рекуррентная комбинация «настоящее + прошлое», маркирующая процесс воспоминания. В настоящем субъект мнемической ситуации признается, что только сейчас начинает осознавать случившееся в полной мере. План прошлого содержит непосредственно воспоминания о ключевых этапах совместной жизни супругов и о попытках противостоять раку. Несмотря на наличие четкой границы между двумя планами, маркированной с помощью обстоятельств времени, настоящее и прошлое тесно связаны друг с другом. На морфологическом уровне взаимопроникновение двух планов проявляется, помимо прочего, в третьем абзаце, где формы Present Indefinite, выражающие субъективную оценку произошедшего с позиции текущего времени, включаются в общий контекст прошлого.

The reality of what losing Katy meant has been coming back to me in recent weeks. I have been remembering the trauma around the diagnosis, the stress and the disorientation, and the impact of the cancer, not just on someone's body but on your own thoughts and feelings. There's the medical bit and then there is the effect on your life, like finding out that you cannot have children. That's a lot to deal with. Katy and I met in 1997 and were married in September 1998. I was 35, she was 30. Then she was diagnosed in January 1999. It was a sarcoma in her gluteus maximus. It was probably only ever going in one direction, to be honest.

There is the tough story - she died in September 2003 - but there is also the good story - we were fortunate in that we had the best 
possible cancer experience we could have expected. Katy got great care from the NHS. The district nurse was fantastic, as were the various doctors she encountered. The consultants' attitude was: "Don't wait for your next appointment - just ring my mobile if you need to.» [...] (The Guardian)

В отличие от битемпоральной структуры, монотемпоральная и политемпоральная не могут претендовать на статус универсальных, так как имеют ряд функциональных ограничений, обусловленных спецификой процесса памяти, вербализуемого мнемическим высказыванием.

Монотемпоральная структура, как и битемпоральная, лежит в основе всех трех типов мнемических высказываний: МДЕ, мнемического монолога и мнемического нарратива, однако в силу своей природы не может служить грамматическим основанием МДЕ «побуждение к запоминанию - реакция» и МДЕ «побуждение к забыванию - реакция», так как специфика содержания данных МДЕ не соотносится с принципом монотемпоральности. Инициирующие реплики указанных МДЕ принадлежат к неопределенному временно́му плану побудительности, тогда как реагирующие реплики локализуют события в реальном времени. При этом темпоральная структура МДЕ «напоминание - реакция» и МДЕ «запрос информации из памяти - реакция» может проявлять свойства как однородности, так и неоднородности. В первом случае ни инициирующие, ни реагирующие реплики данных типов МДЕ не создают иной временно́й план, локализуя события в реальности и относя их к сфере прошлого, настоящего или будущего. Проиллюстрируем наши наблюдения следующими примерами:

"You seem to forget, Luke," I add in lofty tones, "I am a former financial journalist. I know all about money and investment. The bigger the risk, the bigger the profit, I think you'll find.» (Kinsella S. Shopaholic and Baby)

Рассматриваемый пример представляет собой инициирующую реплику МДЕ «напоминание - реакция», принадлежащую плану настоящего. Коммуникант имеет целью актуализировать некоторые сведения, удерживаемые в памяти субъекта мнемической ситуации, при этом номинируемый мнемический процесс мыслится им не как возможный или желательный, а как протекающий в настоящем 
времени, что морфологически передается формой Present Indefinite. При этом легкий оттенок модальности все же присутствует в реплике и маркируется глаголом «to seem», составляющим сложное сказуемое в сочетании с глаголом памяти.

Следующий пример иллюстрирует диалогический обмен между коммуникантами в мнемической ситуации восстановления информации из памяти. Инициирующая реплика содержит запрос о наличии в памяти субъекта определенной информации на текущий момент. В ответной реплике носитель мнемического опыта подтверждает факт хранения интересующей собеседника информации и в качестве подтверждения приводит ряд соответствующих фактов. И реплика-запрос, и реагирующая реплика рассматриваемого МДЕ относятся к темпоральному плану настоящего, что на морфологическом уровне манифестируется формами Present Indefinite глаголов, номинирующих процесс памяти. Формы прошедшего времени, описывающие информационный актант, не являются стержневыми и не влияют на общую темпоральность МДЕ. Актуализации темпорального плана настоящего также косвенно способствуют конструкции с дополнением после глаголов to recall и to remember, позволяющие избежать употребления видо-временных форм, принадлежащих сфере прошлого.

«Do you have any happy memories of your childhood?» I ask quickly, mainly to distract him. He looks pensive for a moment, still running his finger along my skin. "I recall the crack whore baking. I remember the smell. A birthday cake I think. For me. And then there's Mia's arrival with my mom and dad. My mom was worried about my reaction, but I adored baby Mia immediately. My first word was Mia. I remember my first piano lesson. Miss Kathie, my tutor, was awesome. She kept horses, too.» (James E.L. Fifty Shades Darker)

Таким образом, монотемпоральность как принцип организации грамматической структуры высказывания свойственна МДЕ «запрос информации из памяти - реакция», МДЕ «напоминание - реакция», мнемическому монологу и мнемическому нарративу. При этом информационный актант МДЕ и мнемического монолога может быть локализован в настоящем, прошлом или будущем в зависимости от направленности вербализуемого мнемического процесса, тогда как события, описываемые в мнемическом нарративе, априори 
предполагающем ретроспективную ориентацию, принадлежат плану прошлого.

Политемпоральность как способ грамматического структурирования мнемического высказывания имеет ограниченную сферу употребления. Политемпоральные структуры были отмечены нами только среди мнемических монологов и мнемических нарративов, что, на наш взгляд, объясняется природой мнемических процессов, которым изначально не свойственна полинаправленность. Так, в частности, забывание и воспоминание представляют собой своеобразный способ мнемической обработки личного опыта, соответственно, имеют ретроспективную направленность. Запоминание, напротив, имеет целью разместить информацию на хранение для использования в дальнейшем, то есть ориентировано проспективно. Наконец, хранение как поддержание удерживаемой информации в актуальном состоянии и обеспечение беспрерывного доступа к ней относится непосредственно к настоящему. Вербализация всех ключевых процессов памяти в рамках МДЕ, как правило, не представляется возможной. В ходе исследования нами были зарегистрированы отдельные случаи вербального представления не более двух мнемических процессов в условиях диалогического взаимодействия в комбинированных мнемических ситуациях. Однако, в отличие от МДЕ, мнемический монолог и мнемический нарратив являют собой более крупное и объемное коммуникативное пространство, допускающее тематическое многообразие и предоставляющее субъекту мнемической ситуации больше возможностей для самовыражения, что, в свою очередь, создает условия для политемпоральности.

В соответствии с полученными результатами, политемпоральная структура представлена единственной комбинацией «настоящее + прошлое + будущее», которая функционирует в качестве основы темпоральной организации мнемического монолога и мнемического нарратива.

Таким образом, темпоральная структура мнемического высказывания формируется глагольными формами, отражающими субъективное видение процесса памяти как принадлежащего плану временно́й определенности или временно́й неопределенности. В первом случае процессы памяти на морфологическом уровне кодируются видо-временными формами сферы прошедшего, 
настоящего и будущего, тогда как мнемические процессы, мыслимые как ирреальные, репрезентируются формами субъюнктива, императива и модальными глаголами. Распределение глагольных форм в соответствии с темпоральной организацией мнемического высказывания и его типом отражено в таблице 3. Стержневые формы, выступающие независимыми морфологическими маркерами мнемических процессов, выделены жирным шрифтом.

Таблица 3. Распределение глагольных форм в соответствии с темпоральной структурой мнемического высказывания

\begin{tabular}{|c|c|c|c|}
\hline \multirow{2}{*}{$\begin{array}{c}\text { Тип мнемического } \\
\text { высказывания }\end{array}$} & \multicolumn{3}{|c|}{ Тип темпоральной структуры } \\
\hline & монотемпоральный & битемпоральный & политемпоральный \\
\hline \multicolumn{4}{|l|}{$\begin{array}{l}\text { Мнемическое } \\
\text { диалогическое } \\
\text { высказывание }\end{array}$} \\
\hline $\begin{array}{l}\text { МДЕ «побуждение } \\
\kappa \text { запоминанию - } \\
\text { реакияия }\end{array}$ & - & $\begin{array}{l}\text { 1) ирреальное +настоящее } \\
\text { Mod, Subj, Imp, PrI, } \\
\text { PrP, PrC, PrPC } \\
\text { 2) ирреальное+будущее } \\
\text { Mod, Subj, Imp, FI, FC }\end{array}$ & - \\
\hline $\begin{array}{l}\text { МДЕ } \\
\text { «напоминание - } \\
\text { реакиия» }\end{array}$ & $\begin{array}{l}\text { 1) настоящее } \\
\text { PrI, PrP, PrC, PrPC } \\
\text { 2) будущее } \\
\text { FI, FC }\end{array}$ & $\begin{array}{l}\text { 1) настоящее+будущее } \\
\text { PrI, PrP, PrC, PrPC, FI, FC } \\
\text { 2) ирреальное +настоящее } \\
\text { Mod, Subj, Imp, PrI, } \\
\text { PrP, PrC, PrPC } \\
\text { 3) ирреальное+будущее } \\
\text { Mod, Subj, Imp, FI, FC }\end{array}$ & - \\
\hline $\begin{array}{l}\text { МДЕ «запрос } \\
\text { информаичи } \\
\text { из памяти - } \\
\text { реакиия» }\end{array}$ & $\begin{array}{l}\text { 1) настоящее } \\
\text { PrI, PrP, PrC, } \operatorname{PrPC} \\
\text { 2) прошлое } \\
\text { PI, PР, PC, РPC }\end{array}$ & $\begin{array}{l}\text { настоящее +прошлое } \\
\text { PrI, PrP, PrC, PrPC } \\
\text { PI, PP, PC, PPC }\end{array}$ & - \\
\hline $\begin{array}{l}\text { МДЕ «побуждение } \\
\kappa \text { забыванию - } \\
\text { реакияия» }\end{array}$ & - & $\begin{array}{l}\text { 1) ирреальное +настоящее } \\
\text { Mod, Subj, Imp, PrI, } \\
\text { PrP, PrC, PrPC } \\
\text { 2) ирреальное+будущее } \\
\text { Mod, Subj, Imp, FI, FC }\end{array}$ & - \\
\hline $\begin{array}{l}\text { Мнемический } \\
\text { монолог }\end{array}$ & $\begin{array}{l}\text { 1) настоящее } \\
\text { PrI, PrP, PrC, PrPC } \\
\text { 2) прошлое } \\
\text { PI, PP, PC, PPC } \\
\text { 3) будущее } \\
\text { FI, FC }\end{array}$ & $\begin{array}{l}\text { 1) настоящее+прошлое } \\
\text { PrI, PrP, PrC, PrPC } \\
\text { PI, PP, PC, PPC } \\
\text { 2) настоящее+будущее } \\
\text { PrI, PrP, PrC, PrPC } \\
\text { FI, FC }\end{array}$ & $\begin{array}{l}\text { настоящее+ } \\
\text { прошлое }+ \\
\text { будушее } \\
\text { PrI, PrP, PrC, PrPC } \\
\text { PI, PP, PC, PPC } \\
\text { FI, FC }\end{array}$ \\
\hline
\end{tabular}




\begin{tabular}{llll} 
Мнемический & прошлое & настоящее + прошлое & настоящее+ \\
нарратив & PI, PP, PC, PPC & PrI, PrP, PrC, PrPC & прошлое + \\
& PI, PP, PC, PPC & будущеe \\
& & PrI, PrP, PrC, PrPC \\
& & PI, PP, PC, PPC \\
& & FI, FC \\
\hline
\end{tabular}

Сокращения, принятые в таблице 3:

Mod - modal verbs, Subj - Subjunctive mood, Imp - Imperative mood, PrI - Present Indefinite, PrP - Present Perfect, PrC - Present Continuous, PrPC - Present Perfect Continuous, PI - Past Indefinite, PI - Past Perfect, PC - Past Continuous, PPC - Past Perfect Continuous, FI - Future Indefinite, Future Continuous.

\section{Выводы}

Темпоральная структура мнемического высказывания неоднородна и может быть представлена тремя вариантами: монотемпоральным, битемпоральным и политемпоральным. При этом битемпоральная структура обладает признаками универсальности, так как на ее основе формируются мнемические высказывания любого типа.

Темпоральный план мнемического высказывания в английском языке создается видо-временными формами глагола, принадлежащими сферам настоящего, прошедшего и будущего, а также формами субъюнктива и императива и модальными глаголами, репрезентирующими процессы памяти, позиционируемые участниками мнемической ситуации как относящиеся к плану временно́й неопределенности. Среди глагольных форм возможно выделить стержневые, задающие темпоральную направленность мнемического высказывания вне зависимости от других морфологических маркеров, и второстепенные, выполняющие функции дополнительных сигналов временно́й ориентации.

Тип темпоральной организации мнемического высказывания детерминируется когнитивно-коммуникативными условиями его порождения. Соответственно выбор глагольной формы, кодирующей процесс обработки мнемического события на морфологическом уровне, отражает оценку мнемического события участником мнемической ситуации и носит субъективный характер. 
Таким образом, исключительная ассоциированность темпоральности индивидуальной памяти со сферой прошлого, традиционно принимаемая исследователями как данность, не получила подтверждения при анализе фактического языкового материала. Эмпирические данные свидетельствуют о неоднородности темпоральной структуры мнемического высказывания. Истоки стереотипных ассоциаций памяти с прошлым видятся в отождествлении памяти с воспоминанием, то есть процессом реконструкции прошлого опыта, который, в соответствии с представлениями современной психологии об организации когнитивной переработки информации, является лишь одним из четырех базовых этапов мнемической цепи.

\section{Литература}

Артюнина, А.А. (2013). «Мы» и «я» как лингвистические маркеры воспоминаний. Вестник Иркутского государственного лингвистического университета, 3(24), 133-137.

Исхакова, Р.Ф., \& Хомякова, Е.Г. (2009). Память и восприятие: некоторые аспекты языковой репрезентации. Вестник Санкт-Петербургского университета, $1(1), 84-88$.

Крейдлин, Г.Е. (1997). Время сквозь призму временных предлогов. Логический анализ языка. Язык и время (с. 139-151). Москва: Издательство «Индрик».

Огородникова, Л.А. (2012). Подходы к исследованию памяти и мнемических способностей в отечественной и зарубежной психологии. Ярославский педагогический вестник, 2, 308-312.

Рогачева, Ю.Н. (2003). Репрезентация фрейма «память» в современном английском языке. (Дисс. канд. филол. наук). Белгород.

Середа, Г.К. (1985). Что такое память? Психологический журнал, 6, 41-48.

Тивьяева, И.В. (2013). Мнемическое высказывание и процедура его идентификации. Вестник Томского государственного университета. Филология, 372, 45-48.

Тивьяева, И.В. (2017). Когнитивно-коммуникативный подход к исследованию языковой репрезентации процессов памяти. Вопросы психолингвистики, 1(31), 124-139.

Block, R.A., \& Gruber, R.P. (2014). Time perception, attention, and memory: A selective review. Acta Psychologica, 149, 129-133. https://doi.org/10.1016/j. actpsy.2013.11.003

Chafe, W. (1973). Language and Memory. Language, 49(2), 261-281. https://doi. org/10.2307/412454

Clewett, D., \& Davachi, L. (2017). The ebb and flow of experience determines the temporal structure of memory. Current Opinion in Behavioral Sciences, 17, 186193. https://doi.org/10.1016/j.cobeha.2017.08.013

Copmann, K., \& Griffith, P. (1994). Event and story structure recall by children with specific learning disabilities, language impairments, and normally achieving 
children. Journal of Psycholinguistic Research, 23(3), 231-248. https://doi. org/10.1007/BF02139086

Crone, Ph. (2015). Mnemonic Imperatives, Awareness, \& Maximize Presupposition. In California Universities Semantics and Pragmatics Workshop 8. Stanford University. https://web.stanford.edu/ p pcrone/Documents/CUSP_2015.pdf

Crone, Ph. (2017). Raising Awareness with Imperatives. In A. Käplan at al. (Eds.), Proceedings of the $34^{\text {th }}$ West Coast Conference on Formal Linguistics (pp. 122130). Somerville, MA: Cascadilla Proceedings Project.

Faber, M., \& Gennari, S.P. (2015). Representing time in language and memory: The role of similarity structure. Acta Psychologica, 156, 156-161. https://doi. org/10.1016/j.actpsy.2014.10.001

Fuhrman, R., \& Wyer, R.S. (1988). Event Memory: Temporal-Order Judgments of Personal Life Experiences. Journal of Personality and Social Psychology, 54(3), 365-384. https://doi.org/10.1037//0022-3514.54.3.365

Gershman, S.J. (2017). Predicting the past, remembering the future. Current Opinion in Behavioral Sciences, 17, 7-13. https://doi.org/10.1016/j.cobeha.2017.05.025

Graybeal, C. (1981). Memory for stories in language-impaired children. Applied Psycholinguistics, 2(3), 269-283. https://doi.org/10.1017/S014271640000655X

Harner, L. (1976). Children's understanding of linguistic reference to past and future. Journal of Psycholinguistic Research, 5(1), 65-84. https://doi.org/10.1007/ BF01067949

Howard, M.W. (2018). Memory as Perception of the Past: Compressed Time in Mind and Brain. Trends in Cognitive Sciences, 32(2), 124-136. https://doi.org/10.1016/j. tics.2017.11.004

Kintsch, W. (2014). The Representation of Meaning in Memory. New York: Psychology Press. https://doi.org/10.4324/9781315794563

Moore, M.E., \& Johnston, J.R. (1993). Expressions of past time by normal and language-impaired children. Applied Psycholinguistics, 14(4), 515-534. https:// doi.org/10.1017/S0142716400010729

Ochs, E. (1994). Stories that step into the future. In D. Biber \& E. Finegan (Eds.), Sociolinguistic perspectives on register (pp. 106-135). New York: Oxford University Press.

Pennebaker, J.W. (2013). The secret life of pronouns: What Our Words Say About Us. Austin, Texas: Bloomsbury.

Smorti, A., Peterson, C. \& Tani, F. (2016). The Language of Memory: Narrating Memories of Parents and Friends. The Open Psychology Journal, 9(1), 95-110. https://doi.org/10.2174/1874350101609010095

Wang, Y., \& Gennari, S. (2019). How language and event recall can shape memory for time. Cognitive Psychology, 108, 1-21. https://doi.org/10.1016/j. cogpsych.2018.10.003

Xu, X., \& Kwok, S.Ch. (2019). Temporal-order iconicity bias in narrative event understanding and memory. Memory, 27(7), 1-12. https://doi.org/10.1080/09658 211.2019.1622734

\section{References}

Artyunina, A.A. (2013). «My» i «ya» kak lingvisticheskie markery vospominanij [«We» and «I» as linguistic markers of memories]. Vestnik Irkutskogo gosudarstvennogo 
lingvisticheskogo universiteta - Irkutsk State Linguistic University Journal, 3(24), 133-13 [in Russian].

Iskhakova, R.F., \& Homyakova, E.G. (2009). Pamyat i vospriyatie: nekotorye aspekty yazykovoj reprezentacii [Memory and perception: some aspects of language representation]. Vestnik Sankt-Peterburgskogo universiteta - St.-Petersburg State University Journal, 1(1), 84-88 [in Russian].

Krejdlin, G.E. (1997). Vremya skvoz prizmu vremennyh predlogov [Time through temporal prepositions], Logicheskij analiz yazyka. Yazyk $i$ vremya [Logical analysis of language. Language and time] (pp. 139-151). Moscow: Izdatelstvo «Indrik» [in Russian].

Ogorodnikova, L.A. (2012). Podhody k issledovaniyu pamyati i mnemicheskih sposobnostej $\mathrm{v}$ otechestvennoj i zarubezhnoj psihologii [Approaches to studying time and mnemonic capabilities in Russian and foreign psychology]. Yaroslavskij pedagogicheskij vestnik - Yaroslavl' Journal of Pedagogy, 2, 308-312 [in Russian].

Rogacheva, Yu.N. (2003) Reprezentaciya frejma "pamyat'» v sovremennom anglijskom yazyke [Representation of the «memory» frame in contemporary English]. Candidate's thesis. Belgorod [in Russian].

Sereda, G.K. (1985). Chto takoe pamyat? [What is memory?]. Psihologicheskij zhurnal - Journal of Psychology, 6, 41-48 [in Russian].

Tivyaeva, I.V. (2013). Mnemicheskoe vyskazyvanie i procedura ego identifikacii [Mnemonic utterance and how to identify one]. Vestnik Tomskogo gosudarstvennogo universiteta. Filologiya - Tomsk State University Journal of Philology, 372, 45-48 [in Russian].

Tivyaeva, I.V. (2017). Kognitivno-kommunikativnyj podhod k issledovaniju jazykovoj reprezentacii processov pamjati [Cognitive-communicative approach to verbal representation of mnemonic processes]. Voprosy psiholingvistiki - Journal of Psycholinguistics, 1(31), 124-139 [in Russian].

Block, R.A., \& Gruber, R.P. (2014). Time perception, attention, and memory: A selective review. Acta Psychologica, 149, 129-133. https://doi.org/10.1016/j. actpsy.2013.11.003

Chafe, W. (1973). Language and Memory. Language, 49(2), 261-281. https://doi. org/10.2307/412454

Clewett, D., \& Davachi, L. (2017). The ebb and flow of experience determines the temporal structure of memory. Current Opinion in Behavioral Sciences, 17, 186193. https://doi.org/10.1016/j.cobeha.2017.08.013

Copmann, K., \& Griffith, P. (1994). Event and story structure recall by children with specific learning disabilities, language impairments, and normally achieving children. Journal of Psycholinguistic Research, 23(3), 231-248. https://doi. org/10.1007/BF02139086

Crone, Ph. (2015). Mnemonic Imperatives, Awareness, \& Maximize Presupposition. In California Universities Semantics and Pragmatics Workshop 8. Stanford University. https://web.stanford.edu/ pcrone/Documents/CUSP_2015.pdf

Crone, Ph. (2017). Raising Awareness with Imperatives. In A. Käplan at al. (Eds.), Proceedings of the $34^{\text {th }}$ West Coast Conference on Formal Linguistics (pp. 122130). Somerville, MA: Cascadilla Proceedings Project.

Faber, M., \& Gennari, S.P. (2015). Representing time in language and memory: The role of similarity structure. Acta Psychologica, 156, 156-161. https://doi. org/10.1016/j.actpsy.2014.10.001 
Fuhrman, R., \& Wyer, R.S. (1988). Event Memory: Temporal-Order Judgments of Personal Life Experiences. Journal of Personality and Social Psychology, 54(3), 365-384. https://doi.org/10.1037//0022-3514.54.3.365

Gershman, S.J. (2017). Predicting the past, remembering the future. Current Opinion in Behavioral Sciences, 17, 7-13. https://doi.org/10.1016/j.cobeha.2017.05.025

Graybeal, C. (1981). Memory for stories in language-impaired children. Applied Psycholinguistics, 2(3), 269-283. https://doi.org/10.1017/S014271640000655X

Harner, L. (1976). Children's understanding of linguistic reference to past and future. Journal of Psycholinguistic Research, 5(1), 65-84. https://doi.org/10.1007/ BF01067949

Howard, M.W. (2018). Memory as Perception of the Past: Compressed Time in Mind and Brain. Trends in Cognitive Sciences, 32(2), 124-136. https://doi.org/10.1016/j. tics.2017.11.004

Kintsch, W. (2014). The Representation of Meaning in Memory. New York: Psychology Press. https://doi.org/10.4324/9781315794563

Moore, M.E., \& Johnston, J.R. (1993). Expressions of past time by normal and language-impaired children. Applied Psycholinguistics, 14(4), 515-534. https:// doi.org/10.1017/S0142716400010729

Ochs, E. (1994). Stories that step into the future. In D. Biber \& E. Finegan (Eds.), Sociolinguistic perspectives on register (pp. 106-135). New York: Oxford University Press.

Pennebaker, J.W. (2013). The secret life of pronouns: What Our Words Say About Us. Austin, Texas: Bloomsbury.

Smorti, A., Peterson, C. \& Tani, F. (2016). The Language of Memory: Narrating Memories of Parents and Friends. The Open Psychology Journal, 9(1), 95-110. https://doi.org/10.2174/1874350101609010095

Wang, Y., \& Gennari, S. (2019). How language and event recall can shape memory for time. Cognitive Psychology, 108, 1-21. https://doi.org/10.1016/j. cogpsych.2018.10.003

$\mathrm{Xu}, \mathrm{X}$., \& Kwok, S.Ch. (2019). Temporal-order iconicity bias in narrative event understanding and memory. Memory, 27(7), 1-12. https://doi.org/10.1080/09658 211.2019.1622734

\begin{abstract}
АННОТАЦИЯ
Вступление. В работе представлено психолингвистическое видение актуальной для современной когнитивной науки проблемы памяти и времени. Принимая за основу современную модель индивидуальной памяти как лингвокогнитивной системы, включающей процессы запоминания, хранения, воспоминания и забывания, авторы ставят цель рассмотреть специфику языковой репрезентации указанных процессов с учетом их темпоральной ориентации. Настоящая статья посвящена анализу морфологического компонента вербального кода, используемого носителями английского языка для вербализации мнемических переживаний на каждом из этапов когнитивной переработки информации.
\end{abstract}

Методы исследования. Исследовательские процедуры включали контентанализ эмпирического материала, распределение вошедших в выборку 
фрагментов в соответствии с типом мнемической ситуации, структурный и морфологический анализ мнемических высказываний, установление корреляционных связей межуу типом мнемического высказывания и организацией его темпоральной структуры.

Материалы и процедура исследования. Эмпирическую базу исследования составили 7500 фрагментов художественной прозы, публичной, массовой и компьютерно-опосредованной коммуникации, отобранные из открытых англоязычных источников. Коммуникативный контекст регистрировался в базе при условии его соответствия критериям мнемической ситуации, а именно, при наличии 1) субъекта, осуществляющего мнемическую деятельность, 2) вербализуемого процесса памяти, 3) высказывания, репрезентирующего мнемическое содержание в языковых знаках в естественной коммуникации.

Результаты. Полученные результаты указывают на участие в формировании темпоральной организации англоязычного мнемического высказывания видовременных форм группы настоящего, прошлого и будущего и демонстрируют наличие соответствий между типом темпоральной организации мнемического высказывания и когнитивно-коммуникативными условиями его продуцирования, что позволяет сделать вывод о несостоятельности стереотипных представлений об исключительной ориентации памяти на сферу прошлого и фактической неоднородности темпоральной структуры мнемического высказывания.

Ключевые слова: память, мнемические прочессы, мнемическое высказывание, время, темпоральность, временные формы глагола.

\title{
Ощепкова Вікторія, Тів'яєва Ірина. Пам'ять і темпоральність висловлювання
}

\begin{abstract}
АНОТАЦІЯ
Вступ. У роботі представлене психолінгвістичне бачення актуальної для сучасної когнітивної науки проблеми пам'яті і часу. Беручи за основу сучасну модель індивідуальної пам'яті як лінгвокогнітивної системи, яка включає процеси запам'ятовування, зберігання, пригадування і забування, автори мають на меті розглянути специфіку мовної репрезентації зазначених процесів з урахуванням їх темпоральної орієнтації. Ця стаття присвячена аналізу морфологічного компонента вербального коду, який використовується носіями англійської мови для вербалізації мнемічних переживань на кожному з етапів когнітивної переробки інфрормації.
\end{abstract}

Методи дослідження. Дослідницькі процедури включали контент-аналіз емпіричного матеріалу, розподіл фрагментів, які увійшли у вибірку, відповідно до типу мнемічної ситуації, структурний і морфологічний аналіз мнемічних висловлювань, встановлення кореляційних зв'язків між типом мнемічного висловлювання й організацією його темпоральної структури.

Матеріали і процедура дослідження. Емпіричну базу дослідження склали 7500 фрагментів художньої прози, публічної, масової та комп'ютерноопосередкованої комунікації, відібрані з відкритих англомовних джерел. 
Комунікативний контекст реєструвався в базі за умови його відповідності критеріям мнемічної ситуації, а саме, за наявності 1) суб'єкта, який здійснює мнемічну діяльність, 2) вербалізованого процесу пам'яті, 3) висловлювання, яке репрезентує мнемічний зміст в мовних знаках у природній комунікації.

Результати. Отримані результати вказують на участь у формуванні темпоральної організації англомовного мнемічного висловлювання видочасових форм групи теперішнього, минулого і майбутнього та демонструють наявність відповідностей між типом темпоральної організації мнемічного висловлювання й когнітивно-комунікативними умовами його продукування, що дозволяє зробити висновок про неспроможність стереотипних уявлень до виняткового орієнтування пам'яті на сферу минулого й фактичну неоднорідність темпоральної структури мнемічного висловлювання.

Ключові слова: пам'ять, мнемічні процеси, мнемічні висловлювання, час, темпоральність, часові форми дієслова. 